\title{
Relationship Between Parental Involvement and Chinese High School Students' Academic Performance
}

\author{
Ningrui Zhao ${ }^{1, \mathrm{a}, \uparrow}$, Yangshuo $\mathrm{Ye}^{2, \mathrm{~b}, \uparrow}$ and Ao $\mathrm{Gao}^{3, \mathrm{c}, \uparrow}$ \\ ${ }^{1}$ Libral Study Program, New York University, New York City, New York State, 10012, United States; \\ ${ }^{2}$ Department of Psychology, University of Toronto Scarborough, Scarborough, M1C 1A4, Ontario, Canada; \\ ${ }^{3}$ Shanghai Tianyuan High School Affiliated to BFSU, Shanghai City, 201108, China. \\ "These authors contributed equally. \\ *Corresponding author.Email: ${ }^{a} n z 2052 @ n y u . e d u,{ }^{b}$ yangshuo.ye@mail.utoronto.ca, ${ }^{c} 13611937782 @ 163 . c o m$.
}

\begin{abstract}
Parents play a crucial role in children's development, especially in the teenage stage. The present study examined the efficacy of parental involvement for different types of parents on teenagers $(n=92)$. A survey is first conducted to collect patterns of daily parental interactions among high school students. After collecting a sample of descriptions about parent-children interactions, the study then analyzes similar patterns into categories and compares each category with students' academic performance at school, thereby finding each style's effectiveness. As a result, six divisions of parentchildren interactions (academic support, material reward \& punishment, emotional support, future-oriented admonition, valuing independence, and no encouragement) are demonstrated. Moreover, the result suggests that parents who emphasize the importance of learning and discuss the future with their children can positively affect their children's math performance than other interaction methods.
\end{abstract}

Keywords: parental involvement, children's development, academic performance, encouragement, emotional support, material reward, independence

\section{INTRODUCTION}

Parents have strong influences on children's development, and the amount of parental company can alter children's academic achievements and behaviours in school from early childhood through teenage $[1,2]$. Higher amounts of parents' involvement in kindergarten and preschool years have a long-term effect that predicts children's academic achievements and reading abilities in elementary school [3]. Moreover, parents' involvement's association with children's school performance has implications beyond early childhood. For instance, teenagers with highly involved parents have better learning motivations, thereby higher grades [4]. Thus, parents' involvement is an effective strategy to enhance children and teenagers' school performance. The present study investigates the effectiveness of different types of parents' involvement in promoting teenagers' grades in specific subjects.

\subsection{Parental involvement}

Parent involvement is their engagement in children's school life and daily life. Usually, parents' involvement includes participating in children's school events and supervising children's homework and daily activities. Parental involvement is usually measured by time and frequency through surveys and observations. Moreover, to analyse the quality of parent involvement, studies usually consider dimensions like communication, decision-making, and learning at home [5]. Early studies exams that parents involvement and school grade have a positive correlation. For instance, Paul G. Fehrmann et al.'s research finds a positive correlation between parent involvement and teenagers' grades and homework performance [6]. Hedlund also examined the positive correlation between parents' involvement and academic achievement, which adds evidence to previous research [7].

Further studies focus on different parenting styles and measures the influence of each style. To measure parenting style, these studies use the survey to ask 
participants questions related to parent-child interaction. In 2014, Lee and Jennifer's study used a survey to testify the efficacy of parents' expectations and involvement in children's school performance. The result shows that parents' engagement has a higher association with higher grades on younger teens, such as grade 9 children [8]. The research also indicates that parents' expectation has a significant link to higher school performance [8]. For example, parents who have high expectations of the children are more involved in children's school activities, which associate with better school performance. More study on the engagement of autonomous motivation parents and controlled motivation parents shows that both autonomous and controlled motivation parents are more likely to be involved in children's school life. Both two parenting styles have positive effects on children's grades [4].

\subsection{The relationship between parent involvement and academic performance}

There also studies on different forms of parents' involvement, such as home-based involvements, schoolbased involvements, and home-school communication [3]. There is suggestive evidence showing that schoolbased participation is a more efficient way to increase children's school performance [3]. Whereas, home-based participation has no significant effects on children's school performance [3]. More evidence finds that homebased and school-based involvements usually include helping children with homework and communicating with teachers, all of which positively correlate with children's school achievements [3]. Immigrant parents and parents with low SES tend to have less school-based involvement due to language barriers, cultural differences, and working schedules, making these children have difficulties with school work [8]. As a result, strong evidence suggests that home-based and school-based communication are both practical strategies that can help children make higher academic achievements. The possible explanation is that parents who are more involved in school and home have a better understanding of children's' progress in school, making parents more helpful at solving children's problems [3].

Although there is sufficient evidence that shows parents' involvement is positively correlated with academic achievement, most of the studies are quantitative studies. There is a lack of qualitative description of parents' participation. The research on parental companies' descriptions is on a basic level, such as family members and expectations. However, parenting is a complex and important topic, and there are various types of parenting styles. Which parenting style is more efficient and suitable for children's development is always a vital topic. Thus, we need further investigation on the efficiency of different parenting styles in parents' involvement. The study aims to classify parental interventions in more detail and descriptively way in order to further understand the different parenting methods.

\subsection{The present study}

In the present study, we analyse the different types of parents' involvement, encouragement, academic support, material reward \& punishment, emotional support, futureoriented admonition, valuing independence, and no encouragement in high school teens' caregivers. High school students are invited to complete a 20 min survey, asking basic information and parent participation information. The basic information section asks questions about family composition and academic performance. In the second part, the parent participation section, students need to respond to questions about the frequency of parents' involvement and open questions about daily parental interaction, such as "what things could your parents do or say that might make you want to work harder in school to get better grades? " After collecting the survey, a multi regression test is operated to tests the correlation between different parenting styles and students' academic performance. Based on previous research on parent involvement [1-4], we expect students with more active caregivers to perform better in school. Because anxiety level and motivation level are strongly correlated with grade performance $[9,10]$, the hypothesis is (1) students with parents who use academic support, emotional support, future-oriented admonition, and valuing independence strategies have the highest grade in school; (2) teens with parents who do not encourage them to have the worst school performance, because these parenting skills are creating a moderate level of motivation, without pressuring the teens. Although material reward \& punishment creates motivation for teenagers, it also causes stress, thereby preventing students from achieving better grades.

\section{METHOD}

\subsection{Participants}

Participants in this survey research are all recruited from a public high school in Pudong, Shanghai. Among the total of 92 participants, 40 of them are male, and 52 of them are female. Nationality wise, except for three participants from Canada, United States, Taiwan, and Japan, all the rest are Chinese citizens. All participants are either in tenth grade or eleventh grade. Before starting the survey, all participants signed the consent form. Those participants who are below 18 gathered parental consent. Upon getting the consent, questioners were distributed to participants through an online platform. To better interpret the data, two invalid responses are removed from the pool for their lack of relevance to our topics. 


\subsection{Measure}

Student's perception of parental engagement was measured with the Parent Involvement Perception Survey [1]. This survey consists of two parts: structured and unstructured. On this part of the questioner, two questions measured students' perception on parental academic support (eg. Helping me to do homework and asking my progress); two questions measured student's perception on seeking educational guidance (eg. Conference with teacher, attend parent meeting); one question measured student's perception on future oriented admonition (eg. Discuss importance of study on future); one question measure student's perception on emotional support (eg. keep the good job). All these items are rated using a "Likert" type scale, requiring participants to rate their opinion on a four-point scale from 1 (almost always) to 4 (almost never).

The second part of the original survey consists of five open-ended interview questions. For the purpose of this study on exploring the relationship between "student's perception of parental engagement" and "student's academic performance", question three to five were not included in this research because either they require parents to answer or are irrelevant to "student's perception". Two questions are kept direct specifically on student's perception of parental involvement. The first question measures the form of parental engagement that students wish to have; the second question measures forms of parental engagement that students currently have.

\section{PROCEDURE}

This study employs quantitative (six statements) and qualitative (two open-ended questions) to provide a deeper understanding of students' perceptions of parental engagement. The qualitative section aims to find out their general reaction to the most common parental engagement listed in the form of statements. The openended qualitative questions are built upon the quantitative one, aiming to find out a specific parental engagement in real-life situations, including forms of engagements that are not yet present but are expected by students. In contrast to the structured statements-reaction of the first sections, the open-ended was semi-structured, allowing participants to produce a genuine and diverse response, allowing investigators to produce deep interpretations from their responses. Upon getting approval from the high school administration, surveys are distributed online to both tenth and eleventh-grade students. As the prerequisite for participating in the research, all participants have to sign the consent form and gather consent from their parents. The majority of responses are collected two weeks after the first distribution. The cause for such delay can be attributed to the conflict in the schedule between the initial distribution and midterm exam. To increase the success and participation rate of the survey, we've offered small gifts for those who filled out the survey. With the stimulating effect of material reward combing with the gradual closure of the exam, the majority of responses are collected back. Among the 90 valid responses collected, most participants finished the survey in 2 minutes to 4 minutes, with some exceptional cases below 2 minutes. All these durations are sufficient for participants to produce valid results.

\section{DATA ANALYSIS}

SPSS.20 is used to perform descriptive statistics and correlation analysis on qualitative statement reactions. All data from two open-ended questions are transcribed in exact words. According to Saldana, these responses are then coded according to different themes, helping researchers determine the underlying meanings and perspectives within these data [11]. The process of open coding allows researchers to scrutinize the connections between different responses within the group [12, 13]. Analysis of qualitative data is conducted with the guiding suggestions provided by Tracy [14]. First, these responses are organized into two broad categorical themes. Within the first general theme, more specific sub-themes are created base on their different representation of participant's responses. According to Tracy, good qualitative research needs to have a trustworthy analysis to guarantee its conclusion [14]. Thus, to boost the overall strength of this research, we aim to examine high school students during the end when they would have an increasingly tense relationship with their parents. The confidential survey allows participants to write out what they would otherwise not to, thus making our data even more valuable. With the confidentiality to ensure the validity of our data, a careful process of encoding themes categorizes otherwise messy raw data, empowering these data with significance on predicting types of engagements that are favored by students.

\section{RESULT}

\subsection{Descriptive Statistics and Correlations}

Table 1 presents the means and standard deviations for each of the variables, as well as the interrelations between them. Within this set of variables, only variable four (My parent(s) discuss the importance of my education and my future.) and variable six (My parent(s) encourage me to do well in school.) have a strong correlation to math performance. Moreover, variable two (My parent(s) help me with my homework) has the highest rating; variable five (My parent(s) participate in Parent Group meetings and/or activities) has the lowest rating. These two variables do not exhibit a strong correlation to academic performance. Two reasons might account for why only two questions have significant correlations to parental involvement. First, the limitation on the number of participants might have influenced the result. Second, 
academic performances are self-reported by the student, which might contain a certain degree of social desirability bias [15].

Table 1. Descriptive statistic and Correlation

\begin{tabular}{|c|c|c|c|c|c|c|c|c|}
\hline Variables & 1. & 2. & 3. & 4. & 5. & 6. & 7. & 8. \\
\hline Parental engagement 1 & - & & & & & & & \\
\hline Parental engagement 2 & $0.29^{* *}$ & - & & & & & & \\
\hline Parental engagement 3 & $0.44^{* *}$ & $0.31^{* *}$ & - & & & & & \\
\hline Parental engagement 4 & $0.47^{* *}$ & 0.07 & $0.23^{*}$ & - & & & & \\
\hline Parental engagement 5 & $0.41^{* *}$ & -0.08 & 0.20 & $0.63^{* *}$ & - & & & \\
\hline Parental engagement 6 & $0.45^{* *}$ & 0.05 & $0.26^{*}$ & $0.53^{* *}$ & $0.64^{* *}$ & - & & \\
\hline Chinese performance & 0.03 & 0.02 & -0.11 & 0.17 & 0.07 & 0.11 & - & \\
\hline Math performance & -0.12 & -0.07 & -0.00 & $0.23^{*}$ & 0.19 & $0.21^{*}$ & $0.55^{* *}$ & - \\
\hline M & 2.34 & 3.36 & 2.42 & 1.95 & 1.86 & 1.88 & 98.68 & 104.42 \\
\hline$S D$ & 1.04 & 0.96 & 0.96 & 0.99 & 1.11 & 1.07 & 15.18 & 22.18 \\
\hline
\end{tabular}

Note. Parental engagement 1-6 each represent the six statements about parental engagement; $\quad{ }^{*} \mathrm{p}<.05 ; * * \mathrm{p}<.01 ; * * * \mathrm{p}$ $<.001$.

\subsection{Analysis of Qualitative Data}

Table 1 presents the means and standard deviations for each of the variables, as well as the interrelations between them. Within this set of variables, only variable four (My parent(s) discuss the importance of my education and my future.) and variable six (My parent(s) encourage

Table 2. Question 14: What CAN your parents

\begin{tabular}{|c|c|c|c|c|c|}
\hline Theme & Subtheme \& Typical response & $\begin{array}{l}\text { Number of responses } \\
\text { within each theme }\end{array}$ & $\begin{array}{c}\text { Theme } \\
\text { Frequency }\end{array}$ & $\begin{array}{l}\text { Number of Reponses } \\
\text { within each subtheme }\end{array}$ & $\begin{array}{l}\text { Subtheme } \\
\text { Frequency }\end{array}$ \\
\hline \multirow[t]{4}{*}{ encouragement } & $\begin{array}{l}\text { 1. Academic support (analyze mistakes } \\
\text { in tests) }\end{array}$ & 71 & $78.88 \%$ & 5 & $7.04 \%$ \\
\hline & $\begin{array}{l}\text { 2. Material reward (give money) and } \\
\text { punishment (not giving birthday gift) }\end{array}$ & & & 30 & $42.25 \%$ \\
\hline & $\begin{array}{l}\text { 3. Emotional support (keep at it, you can } \\
\text { do it) }\end{array}$ & & & 36 & $51.43 \%$ \\
\hline & $\begin{array}{l}\text { 4. Future oriented admonition (work } \\
\text { hard so that you can get a good job) }\end{array}$ & & & 8 & $11.2676 \%$ \\
\hline $\begin{array}{l}\text { No } \\
\text { encouragement }\end{array}$ & & 19 & $21.11 \%$ & & \\
\hline
\end{tabular}

Table 3. Question 15: What ARE your parents doing to make you work harder in school to get better academic performance?

\begin{tabular}{|c|c|c|c|c|c|}
\hline Theme & Subtheme \& Typical response & $\begin{array}{l}\text { Number of responses } \\
\text { within each theme }\end{array}$ & $\begin{array}{l}\text { Theme } \\
\text { Frequency }\end{array}$ & $\begin{array}{l}\text { Number of Reponses } \\
\text { within each subtheme }\end{array}$ & $\begin{array}{l}\text { Subtheme } \\
\text { Frequency }\end{array}$ \\
\hline \multirow[t]{5}{*}{ encouragement } & $\begin{array}{l}\text { Academic support (analyze mistakes } \\
\text { in tests) }\end{array}$ & 68 & $75.56 \%$ & 19 & $27.94 \%$ \\
\hline & $\begin{array}{l}\text { 2. Valuing impendence (respect my own } \\
\text { arrangement) }\end{array}$ & & & 29 & $42.65 \%$ \\
\hline & $\begin{array}{l}\text { 3. Material reward (give money) and } \\
\text { punishment (not giving birthday gift) }\end{array}$ & & & 10 & $14.71 \%$ \\
\hline & $\begin{array}{l}\text { 4. Emotional support (keep at it, you can } \\
\text { do it) }\end{array}$ & & & 11 & $16.18 \%$ \\
\hline & $\begin{array}{l}\text { 5. Future oriented admonition (work } \\
\text { hard so that you can get a good job) }\end{array}$ & & & 3 & $4.41 \%$ \\
\hline $\begin{array}{l}\text { No } \\
\text { encouragement }\end{array}$ & & 22 & $24.44 \%$ & & \\
\hline
\end{tabular}




\subsubsection{Theme 1: encouragement}

Parents play an important role in determining student's perceptions, either negative or positive to school, based on their different forms of developmental influence [16]. Positive influence usually exhibits itself in the form of encouragement. Such encouragement boosts the self-confidence and self-esteem of students, thus increases students' inclination to participate in a leadership role in extracurricular activities at school and maintain a good academic record [17].

\subsubsection{Academic support}

Through the analysis of responses from these two open-ended questions, a stark contrast for academic support between the first expectation question and the second reality question in terms of theme frequency is clearly shown. Comparing to the significant proportion of 27.94 percent of the second question, the 7.04 percent in the first question is much smaller. Within the subtheme of academic support for "reality" question, it is noticed that a third of them is related to "after school class and tutoring". Participant 51 mentions that "his mom would contact the agent in after school class to arrange tutorial for him if he does not do well in tests." Participant 76 writes that "arrange tutoring for me". This form of academic support related to tutoring stands in contrast to the "personal supports", such as analyze mistakes in tests that make up the rest of "reality" question and all of the academic support responses in the "expectation" question. Presumably, negative interaction of the student with the "tutoring" form of academic support in real life might give them an overall negative perception of the academic support, thus not considering it a favorable form of encouragement when answering the "expectation" questions.

\subsubsection{Material reward \& punishment}

In both expectation question (question two) and reality question (question 1), material support holds an important place. However, there is still a distinct contrast on this topic between the expectation question and reality question. It is noted that while the material reward \& punishment of expectation question have a subtheme frequency of 42.25 percent, almost half of all subthemes, material reward \&punishment only makes up 14.71 percent frequency in reality question. Within the subtheme of material reward and punishment, most of the responses are financially oriented. In the expectation question, participant 33 writes that "my parents would give me a big red envelope (same as money) when I get a good grade. In the reality question, participant 70 writes that "if I get good grade my parent would reward me with more pocket money, whereas if I do bad, they will deduct my pocket money". The contrast in the frequency of this subtheme between the expectation question and reality question suggests that while students want material benefit, their parents do not necessarily favor this reward method.

\subsubsection{Emotional Support}

According to Maslow, human motivation to perform well is based on the social need for love [18]. While students who get love from their parents feel secure and motivated, those who did not receive love sometimes demonstrate sadness and even desperation [19]; such negative emotions would affect the quality of life and decrease the academic performance of students when they lose morale. As demonstrated in our analysis of two openended questions, emotional support indeed plays a big role in motivating students to work hard at school. For the first expectation question, 51.43 percent of students report that they want emotional supports. While in the second reality question, the frequency is much lower, emotional support nevertheless takes up 16.18 percent of frequency. Some of the most common responses in emotional support subtheme all involves "encouragement when getting bad grades". In expectation question, Participant 31 writes that "acknowledge my strength and encourage me when I am not doing well". Participant 81 writes that "don't feel inferior when you get a bad grade". The contrast between expectation question and reality question in terms of emotional support might result from parents' general ignorance of students' need for emotional support. Many factors, including lack of communication, which is common for high school student at the age of 16 and 17 , could result in such different between reality and expectation.

\subsubsection{Future Oriented Admonition}

Subthemes for future oriented admonitions did not reach a significant amount in both questions. In the first expectation question, this subtheme takes up 11.26 percent; in the second reality question, this subtheme takes up only 4.41 percent. Most of responses within this subtheme relate to "future job-seeking". Participant 64 in expectation question writes that "your hard work today will give you a better chance to find a well-paying job." Participant 61 writes that "if you don't work hard now, you can't get a college degree and find a decent job". The fact that future-oriented admonition is not mentioned so much might not necessarily reflect the lack of significance that parents place on student's future. In fact, the deep correlation between "academic performance" and "future welfare" is so much entrenched in Chinese culture that it almost becomes a subconscious consensus. In this sense, students and parents might just not think of futureoriented admonition as worth mentioning since both know its significance. 


\subsubsection{Valuing Independence}

The subtheme valuing independence only appeared in the second reality question. Moreover, this subtheme valuing independence takes up almost half of the entire subtheme with a frequency of 42.65 percent. For high school students at the age of 16 or 17 , allowing them to independently grow can be fruitful. Most responses for this subtheme involve "respect". Participant 36 writes that "respect my own plan" Participant 55 writes that "son, you are in charge of yourself." Taking up almost half of the entire subtheme, valuing independence reveals both positive and negative implications for student's academic performance. While valuing independence can indeed promote students' own ability to make academic plans, some other students would then misuse this opportunity and use it to engage in matters that are not academically related. In this sense, if parents still adhere to the principle of valuing independence, this might simply reflect their lack of proper guidance. In this sense, participant 45's response offers a great method: "respecting my thought and helping me through difficulties". With synergy between active control and independence valuing, student's academic potential can be mostly fulfilled.

\subsubsection{Theme 2: no encouragement}

The general theme of no encouragement each takes up around a fifth percent of all themes. While no encouragement gains 21.11 percent in expectation questions, it gains 24.44 percent in reality questions. According to Comer \& Hayes, parents' negative perceptions of parental engagement might decrease student's level of participation and academic performance in school [20]. If these 20 percent of students indeed lack the necessary parental engagement, their academic performance would undoubtedly be negatively influenced. On the other hand, through analysis, it is found that most of the responses in this theme are short phrases like "no" or "nothing". This phenomenon might simply reflect participants' unwillingness to elaborate their answers.

\section{DISCUSSION}

The present study examined the relationship between each dimension of parents' participation and students' academic performance by questionnaires surveys and interviews.

\subsection{Results of quantitative research}

From the results of the questionnaire survey, there are great differences in different dimensions of parents' participation. Parents are more inclined to supervise their children's academic participation in the family, followed by communication with their children, and less involved in school activities and school communication.
Compared with the six ways of participation proposed by Epstein [5], "family participation" is the main way of participation, while "school participation" is relatively lacking. Family participation is the most direct way for parents to participate, so it will become the main way for parents to participate. School participation is a long-term weakness of Chinese parents' participation. However, these two points are not shown in children's performance. What is related to this is that parents' discussion and communication with students positively affect students' achievement and even learning motivation. In terms of discussion and feedback on children's performance, Chinese parents still take material rewards as the main way, and the rest is to discuss goals or ideals with their children. This reflects that now parents are starting to encourage their children by single reward and paying attention to spiritual fullness.

\subsection{Results of qualitative research}

The results of qualitative research are very different from those in the West. The differences in parents' participation are mainly due to the differences in family culture and educational environment. In the West, there are relatively perfect laws, forms and procedures, complete systems and organizations, and all aspects of society are closely linked and supervised. On the contrary, China's overall situation is not as good as that of western countries. Laws and regulations, the practice of education departments and the specific types of parents' participation are superficial. These are the differences between Chinese and Western parents in the degree of participation, which need to be paid attention to and improved. This is consistent with previous studies abroad, some dimensions of parental participation have a positive impact on children, and even some will have a negative impact [21, 22]. Parents with high education background show concern, understanding, and encouragement attitude to students, and will not interfere too much; parents with low education background may have some negative effects and interference on students' study and life. The reason: some parents participate in the students' study and life after the specific problems, and the communication between teachers and parents is also after the students' problems. This shows that parents' participation is not perfect. Develop the right home school positive communication. Second, parents' participation in homework is more formalized and fixed, just checking and correcting these jobs according to the traditional signature. This will also make students dependent on their parents and will not study independently. Some parents in the way of communication are also relatively old, mainly in reward and punishment, so that students have certain blindness in learning. The results also show that many parents have begun to pay attention to parent-child communication with the development of the times. Start to let students understand the purpose of learning to urge students to learn, have a positive impact. The original 
intention and Prospect of this study are to find advantages and disadvantages in observing the relationship between parents' participation and students' performance in this competitive environment. Parents and schools should pay more attention to the relationship between home and school and strengthen the complete understanding of parents and teachers for students' performance.

Generally speaking, parents' participation is not the more, the better, but should pay attention to the ways and specific dimensions of participation. With positive guidance, it will have a positive impact on students' learning performance.

\section{CONCLUSION}

From the analysis of descriptive statistics and correlation, it is found that future and educational related conversation between parents and students have a high correlation to math performance. This relationship is partially due to Chinese parents' long-standing emphasis of math skill. Aside from this, parents personal support and parent teacher meeting receives the highest rating. From the analysis of qualitative data, it is found that the majority of students expect to get material reward ad emotional support for good academic performance. On the other hand, parents themselves have a quite different idea on what should be the best form of encouragement: nearly half of students report that their parents value their independence, and one third of them reports that their parents provide academic support for them. This disparity between parents' action of encouragement and student's expectation reveals a need for more communication between parent and students.

There are also some deficiencies in the research. Most of the students who participate in the questionnaire survey are from the same school, mainly high school students. Therefore, the results presented are not comprehensive, which are related to the performance of high school students in Shanghai and parents' participation. And because some students are not serious about the questionnaire, it will have a slight impact on the results. In the future, more studies are needed to test whether the same results can be obtained in a larger sample size. The study should also be tested at different age groups and locations to determine whether the same pattern exists in diverse populations. Moreover, future research should also focus on methods other than selfreporting to avoid the limitations of self-reporting, such as social demand bias.

\section{APPENDIX}

Parental involvement survey scale

\begin{tabular}{ll}
\hline high range of involvement & $1.0-2.0$ \\
\hline middle range of involvement & $2.1-2.9$
\end{tabular}

\begin{tabular}{ll}
\hline low range of involvement & $3.0-4.0$ \\
\hline Consent Form
\end{tabular}

Consent Form

Ningrui Zhao ---nz2052@nyu.edu (401)212-3096

Yangshuo Ye--- yangshuo.ye@mail.utoronto.ca (3062614936

\section{Ao Gao--- 13611937782@163.com}

You are invited to take part in a research study regarding Parenting style. If you are below the age of 18 , please obtain your parent's consent before you participate in this research. Pressing continue means that your parent has permit you to participate in this research.

What the study is about: Parents have strong influences on children's development, and different parenting styles can alter children's characteristics, interest areas, and even academic performance. This survey is the first part of our research study with the purpose to find out about the relationship between parenting style and student's academic performance.

What you will be asked to do: As a participant, you will be asked to answer the questions in the survey. The survey allows the researchers to document your perceptions, ideas, and experiences as a high school student in relation to your parent.

Risks: This part of our research is both qualitative and quantitative. There are no known risks to participating in this focus group. The primary focus will be how you feel and perceive the parenting style. Your answer will be recorded for analysis.

Taking part is voluntary: Taking part in this study is completely voluntary. If you choose to be in the study, you can also choose to withdraw at any time without consequences. Participating in this study does not mean that you are giving up any of your legal rights.

Your answers will be confidential: The records of this study will be kept private. Data will be kept on data files and then destroyed once the discussions have been fully transcribed. Transcriptions of the discussion will be kept on a personal computer to which only the researchers have access. Any report of this research that is made available to the public will not include your name or any other individual information by which you could be identified.

If you have questions or want a copy or summary of the study results: Contact any researcher listed at the email address or phone number above. You will be given a copy of this form to keep for your records. If you have any questions about whether you have been treated in an illegal or unethical way, contact Ningrui Zhao at nz2052@nyu.edu

Parental Involvement Survey 


\section{Part 1: Basic Information}

1. grade level

2. sex of birth

\begin{tabular}{|l|l|}
\hline Male & \\
\hline Female & \\
\hline
\end{tabular}

3. Please write down your grade for Math and Chinese in first semester

\begin{tabular}{|l|l|}
\hline Math & \\
\hline Chinese & \\
\hline
\end{tabular}

4. Please select the most appropriate description of the person you currently live with from the table below

\begin{tabular}{|l|l|}
\hline Mother & \\
\hline Father & \\
\hline Step mother & \\
\hline Step mother & \\
\hline Else (Specify) & \\
\hline
\end{tabular}

Goal of the parent involvement survey: to examine student perceptions of parent involvement and to ascertain if high school students who perceive parent involvement as high achieve higher GPA's than those students who perceive parent involvement at a low level.

\section{Part 2: Parent Involvement Perception Survey}

$(1=$ Almost Always, $2=$ Frequently, $3=$ Seldom, $4=$ Almost Never)

1. (A) My parent(s) discuss my work and progress with me.

2. (B) My parent(s) help me with my homework

3. (C) My parent(s) attend conferences with my teachers.

4. (D) My parent(s) discuss the importance of my education and my future.

5. (F) My parent(s) participate in Parent Group meetings and/or activities.

6. (E) My parent(s) encourage me to do well in school.

\section{Part 2: Parent Involvement Perception Survey}

1. what things could your parents do or say that might make you want to work harder in school to get better grades?

2. What things do your parent(s) do or say to make you want to work hard in school to get the best grades you can?

3. If explanations are needed for any part of this survey please note them in the box below.

\section{REFERENCES}

[1] Hedlund, T. L. (2010). Parental involvement in secondary education: Perception of parental. involvement and academic outcomes (Order No. AAI3405002). Available from Sociological Abstracts. (818806754; 201076949). Retrieved from http://proxy.library.nyu.edu/login?url=https://wwwproquest-com.proxy.library.nyu.edu/dissertationstheses/parental-involvement-secondaryeducation/docview/818806754/se2? accountid $=12768$

[2] Hornby, G., \& Witte, C. (2010). Parent involvement in rural elementary schools in New Zealand: A survey. Journal of Child and Family Studies, 19(6), 771-777. https://doi.org/10.1007/s10826-010-93685

[3] Anthony, C. J., \& Ogg, J. (2019). Parent involvement, approaches to learning, and student achievement: Examining longitudinal mediation. School Psychology, 34(4), 376-385. https://doi.org/10.1037/spq0000282

[4] Cheung, C., \& Pomerantz, E. M. (2012). Why does parents' involvement enhance children's achievement? The role of parent-oriented motivation. Journal of Educational Psychology, 104(3), 820-832. https://doi.org/10.1037/a0027183

[5] Epstein, J. L. (2010). School/Family/Community Partnerships: Caring for the Children We Share. Phi Delta Kappan, 92(3), 81-96. https://doi.org/10.1177/003172171009200326

[6] Paul G. Fehrmann, Timothy Z. Keith \& Thomas M. Reimers (1987) Home Influence on School Learning: Direct and Indirect Effects of Parental Involvement on High School Grades, The Journal of Educational Research, $\quad 80: 6, \quad 330-337$, DOI:10.1080/00220671.1987.10885778 
[7] Hedlund, T. L. (2009). Parental Involvement in Secondary Education: Perception of Parental Involvement and Academic Outcomes. ProQuest.

[8] Lee, S., \&amp; Jennifer, S. A. (2014). Parent Engagement in Science with Ninth Graders and with Students in Higher Grades. School Community Journal, 24, 1st ser., 17-36. doi:https:/files.eric.ed.gov/fulltext/EJ1032238.pdf

[9] Lee, S., Elena, L., \& Jennifer, S. A. (2011). Predictors and Outcomes of Parental Involvement with High School Students in Science. School Community Journal, 21(2), 81-98. Retrieved from https:/eric.ed.gov/?id=EJ957128

[10] Pang, X. (2020). The influence of parents' attitudes towards mathematics on students' mathematics achievement: The chain mediation effect of mathematics motivation and mathematics anxiety. Youth Journal http://www.cqvip.com/qk/87739x/202001/7100926 $181 . \mathrm{html}$

[11] Saldana, J. (2008). The Coding manual for qualitative researchers. Retrieved from www.sagepub.com/upmdata/24614_01_Saladana_Ch_01.pdf

[12] Neuman, W. L. (2006). Social research methods: Qualitative and quantitative approaches (6th ed). Boston, MA: Pearson.

[13] Strauss, A. \& Corbin, J. (1998 [1990]). Basics of qualitative research: Techniques and procedures for developing grounded theory. Thousand Oaks, CA: Sage.

[14] Tracy, S. J. (2010). Qualitative quality: Eight 'bigtent' criteria for excellent. qualitative research. Qualitative Inquiry, 16, 837 - 851 .

[15] Wasylkiw, L. (n.d.). Social desirability bias. Encyclopedia of Social Psychology. doi:10.4135/9781412956253.n527

[16] Berthelsen, D. \& Walker, S. (2008). Parents' involvement in their children's education. Family Matters (79), 34-41

[17] Patrikakov, R. P., Weissberg, S., Redding, S, \& Walberg, E. N. (2006). School-family partnerships: Promoting the social, emotional, and academic growth of children. New York, NY: Teachers College Press.

[18] Maslow, A. H. (1943). A theory of human motivation. Psychological Review, 50(4), 370- 396. doi:10.1037/h0054346

[19] D'Cruz, H., \& Stagnitti, K. (2010). When parents love and don't love their children: Some children's stories. Child \& Family Social Work, 15(2), 216-225. doi:10.1111/j.1365-2206.2009.00662.x

[20] Comer, J. P. \& Haynes, N. M. (1991). Parent involvement in schools: an ecological. approach. The Elementary School Journal, 91, 271-277.

[21] Trivette, p.,Anderson, E.,Singh,K.,Bickley,P.,Keith, T. Z.\&Keith, P. B.(1995).The effects of four components of parental involvement on eighth grade student achievement: Structural analysis of NELS88 data. School Psychology Review, 24(2), 299-317

[22] Fan, X.(2001). Parental involvement and student academic achievement:A growth modeling analysis. The Journal of Experimental Education,70(1), 27-61 